\title{
The National Policy and Legal Reality: This Trend of Social Pervasiveness will Continue...,
}

\section{Said Alavi Kolambil*}

Department of Pharmacology, Rajasthan University of Health Sciences/Sanjeevan College of Pharmacy, India

*Corresponding Author: Said Alavi Kolambil, Department of Pharmacology, Rajasthan University of Health Sciences/Sanjeevan College of Pharmacy, India.
Received: July 17, 2021

Published: August 14, 2021

(C) All rights are reserved by Said Alavi

Kolambil.
We heard hues and cries from all parts of the world, surely, the major towns were struggling under the strain of government cuts enough without having to conjure additional funds from thin air to meet requirement of some of the most desperate people, it found policy makers struggling to resolve this problem, recent incidents clearly shown how the rotten hand faced by the private health insurance providers, even one who announced comprehensive health coverage pack without any sub limits. Among other things, we can't deny the fact,substandard medicines and commodities found flourished in the market, it needs to pay higher margin of profit by the common man, no doubt the tense of atmosphere made everyone suffocated we can't forget how private health care providers looted the wretched man's money on this pandemic situation.

United nation (UN), Article 12, in forum 22, international covenant of economic, social cultural rights clearly mentioned that everyone has right to enjoyment for highest attainable standard health services, but situation entirely different, not only in developing countries but also developed countries [15], to access a good health services, at free cost for the poorest man still in dreamy stage. Other inter alia related poor infrastructural, human power shortages, lack of transparency and accountability in existing public health care system, shortage of funds to buy essential medicines, equipment and other diagnostic facilities.

WHO statement clearly shows that low income countries 45 higher share of private health expenditure rather than middle and high income countries. In India more than three fourth people depend on private sector, the pathetic condition shows that 0.38 million people committed suicide during tenure of 2001 to 2015, due to financial liabilities to meet health care cost. (national crime records bureau), similar statement made by NSSO- National Sample
Survey Office), surpassed decade (2002-2012) doubled loan granting due to health care needs Recent highlights shows in times of India, per capita public health expenditure steadily increased 2009 2010 at around 612 Indian rupees to 1112 in 2015-2016, changed at rate of $5 \% 2018$. The national health postulated 34 percentage people covered health insurance in 2016-2017, focused on specified categories only. It is needs to change our policy, instead of too moderate to please the people, too democratic to the nobles.

According to latest figure In India meagerly spending on health sector (0.9percent) compare to other less developed countries $(2.8 \%)$. It was proposed to raise the funds, the country's expenditure on public health services to 2.5 percent of the GDP by 2025 National health accounts (NHA) in 2014-15, provided data shows that government health expenditure 1108 rupees per annum, it comes approximately 3 rupees per day for each person. The statement shows that out of pocket expenditure per annum 2394, the situation not different in Pakistan 65.2\% which found world average 18.2 percentages. The reviewed article highlighted on health sector in Pakistan, emphasized on unethical practices of traditional healers, the health seeking behavior of community which partially influenced by sociocultural beliefs and inadequate infrastructural and human resources in public health care system, however, the immunization programs reached good level, certain extent through service provided primary health center [8]. This incident shows with the selective investment and other centralization measures, de facto especially through immunization were being benefitted whole community $[12,16]$.

The neighboring countries in Bangladesh, the situation is not different, total healthcare of percentage utilized 3.1\% (2014) on GDP. The people made expenditure on private sector, were boom- 
ing since past years, however spending public on health sector found stable. The Private sector providers made informed choices to the patient, highly expectation of patient in health providers and in private hospital settings, householders decision based convenience, improved socio economic status of the people, unfortunately, lack of funding in public health sector, dilapidated infrastructural utilities, attracted more people towards the private health care system $[6,10,19]$.

The global health base data shows current health expenditure on made on GDP in some of the south Asian Afghanistan (10.2), Bangladesh (2.37), Bhutan(3.45), India (3.66), Myanmar (5.09), Nepal (6.29), Pakistan (2.75), Sri Lanka (3.89) And in Middle East countries, Bahrain (4.87), Egypt (4.64) Ian (8.1), Iraq (3.31), Israel (7.31), Jordan (5.47), Kuwait (3.9), Oman (4.29), Qatar (3.08), Saudi Arabia (5.74) turkey (4.31), Syrian Arab republic (3.57), UAE (3.52), Yemen (5.6) so on.

On topic of "Rebuilding health care in Iraq" illustrated view on professional colleagues needs to provide technical supports, currently health care system shackled, being faced war indemnities [5]. The publication provided health information on Iraqi population [7], clearly mentioned four parameters to rejuvenate existing health system, programs for personal healthcare management, and proper delivery of health care services, this stratagem encouraged to conduct research and other relevant activities, and emphasized one for public so on. Iraqi ministry of health with collaboration of British government assisted health care providers through various training program improved little bit this condition. The article found regarding burden of financial cost, poor outcome especially in public health services; Saudi government has taken initiative steps to encourage of private health across these countries, as part of these project free loans provided to construct private health care facilities. However, private sector focused on expatriates, out of them treated 80 percentages belongs to Saudi citizens. In past, Saudi government focused on primary health care Centre as a decentralized unit, these network system even found in remote village area, could accessed the common man, and other complicated cases referred to higher center, which were being contributed in successive rate of immunization programs, maternity care, and to prevention of other endemic diseases so on.
We can't deny the fact primary health care center not merely, to cure diseases, but also concerned both preventive and promotional activity [4].

However the article viewed, lack of educational background and technical experts from own part of nationalities major hindrance onto provide better therapeutic care, because of foreigners staying this country in short span of time it takes time to learn sociogenic understanding of this people, the facts not only limited to provide continuous services for own man but also the investor look on short run capital investment because once they need to depart from this country, definitely he/she was not interested at all to implement code of advancement of science and technology in their practicing system.

Saudi nationalities deployed as a physician devoted their services in ministry of health meagerly 5 percentages compare to total private practiced physician working in Ministry of Health. Once this countries borne third of health expenses by the government, in which $62 \%$ patient treated by the public health system, remaining 25 percentages only carried out the private sector.

Now the situation changed, Increased public awareness on health, promoted needs for specialty health care concern (often not needed) found as an alternative opportunity to exploit patient by the private health sector, we were familiar in terms of private sector physician gives substantial incentives to recruit outpatient enrolled as inpatient (not required one) and conducting unnecessary tests, and other procedures, things found overutilization of emergency department by disease mongering, the private sector purely tried to compete in sister's business establishment, however the cost ultimately burdened on patient, One part of health insurance private sector provider's adopted costeffective treatment regimen, e.g.insteadof hiring of own nationalities preferred cheaper source from outsiders, it was not only limited to build technical capacities from own nationalities, but also poor interaction between physician and patient gives poor end result in therapeutic regimen. The fact not only limited the counterpart region drugs preferred drugs with more profitable one (concerned pharmacist in charge of hospital starts negotiation with pharmaceutical agents for bulk purchase with huge offer, finally these imprinted retail price burdened on patient, we can't deny the fact incentives for consultants accord- 
ing to sales tempted to over prescribe drugs and other consumable. It should be advocated consequence of antibiotics misuses not only limited individual but also suffered whole community.

On topic of Health care forecasting in United Arab Emirates gives short note in JHHSA summer 2016 [11,17], pointed out following facts to deliver proper health services, One of the posited hindrances like lack of skilled human resources on overall managing activities to retain quality of services in efficient manner with one found budgetary limit, it also noted disparities on health care distribution in western region of emirates, The government looks upon public private partnership programs to utilize finance in efficient manner (e.g. Al maliha poly clinic), The nation also found mandatory health insurance scheme for own people as well as expatriate, it made significant improvement in health care system, however recently public contribution steadily decreasing, found an alternative opportunity for looting money by the private health sector through by exploiting government implemented programs. However shortages in priority services were noted on wellequipped infrastructural facilities for handling critical cases like in cardiac vascular incidents, cancer, and respiratory tract disease so on. The later statement supported the above facts, peer reviewed on seventeen articles, highlighted, the UAE provided world class health care system through by implementing policies like mandatory health insurance scheme, favored for investing private health care sector, and on by separation of planning, regulatory responsibilities from on part of provider functions [14], the big question is whether or not they will be able to develop enough power to stop this exploitation altogether, and to build national capacities on long run.

The studies hinted need for improvement in education amongst the Qatari nationalities in field of health care system to support country man, no one can withstand without educational, high skilled especially in complex health care field [11]. The reviewed data spotted $[9,18]$, there was, of course, hindrance to man having lack of communication to achieve proper therapeutic goal, in where, out of eighty percentage of population found expatriate. The initiatives were taken by Weill medical college with cooperation of Hamad medical center, the American universities facilitated education in medical field. Investment of Sidra medical research center was another footstep in medical field. We can't deny fact that significant effort have taken to promote health education amongst the people by cooperation between GCC countries through by telecon- ferencing technology and on by sharing planned medical records.

As far it discussed importance of renovating public health care system, and to keep eye on trouble shoots which were faced on health and education systems. Some of the important components have discussed which hindered on easy going health notion. More importantly, Out of pocket expenditure: individual should be paid to the health care providers to them deployed services; here the citizen has the right to get good health services from own countries.

WHO strongly recommended for financing to save this people, rise funds through central and state revenues, by giving loans and grants for promoting investment in health care settings, implement compulsory premium for stable functioning of health insurance, needs to encourage donation, and ensure justifiable salary for health care providers so on, here sickness is not an individual misfortune and calamities not limited personnel one, affected whole communities.

Leaders of nation and policy makers have responsibilities on this regards. Studies shows that with an intention to gauge private sector's commitment as health role players, outputs were shamefully, and absolutely they found access of health care services denied to thepoorer.

Private sector skewed the balance towards urban biased, tertiary level health services, targeted overwhelming profit modules rather than rationality in treatment [2].

It needs to make investments in training and support system to ensure data quality services in health [3], studies shows that planners should be appraised on interdisciplinary approaches to enact policies, to encourage service utilities in better way in health, welfare and educational services Here author proposed the best example Kerala state, located southern part of India, one of the state found highest population density, out of 34 million mobs restricted in area of 38,863 $\mathrm{km}^{2}$ with more than 5 million migrant workers, and 4 million people were found working abroad. The strategies during times of crises like, nipah virus outbreak, floods of 2018 and recent incidents took placed covid-19 how them survived this pandemic situation, no doubt other than decentralized, well framed public health care system $[1,20]$ supported for the misery, needy man, It is remarkable that we look down education, cooperation and coordination amongst the communities have major role on survival of this disastrous effects [21]. 
As this policies was to be entered into without usual capital, it may not be easy to conjecture where those means, that will still be indispensable to every such undertaking, were to be obtained through Health and education.

\section{Bibliography}

1. Gregson B., et al. "Inter-professional collaboration in primary health care organizations". Occasional Paper 52. London: Royal College of General Practitioners (1991).

2. Mahal A., et al. "Benefits from public health spending in India". New Delhi: National Council of Applied Economic Research (2001).

3. Andrew Furber and Paul Johnstone. "Rebuilding health care in Iraq". Journal of Epidemiology and Community Health 58 (2004): 889-890.

4. Walston S., et al. "The changing face of healthcare in Saudi Arabia". Annals of Saudi Medicine 28.4 (2008): 243-250.

5. Shayne Cox Gad. "Clinical Trials Handbook". John Wiley and Sons (2009): 118.

6. Weeresinghe MC and Fernando DN. "Access to care in plural health system: concerns for policy reforms". Journal of the College of Community Physicians of Sri Lanka 14 (2009): 39-45.

7. Aamir Al Mosawi and Hasnawi SMA. "Iraq health care system: an overview". New Iraqi Journal of Medicine 5.3 (2009): 5-13.

8. Azhar Hussain. "Amongst drug sellers named as using the potential community pharmacies to promote rational drug use in Pakistan: an opportunity exist or lost?". Journal of Pakistan Medical Association 62.11 (2012): 1217-1222.

9. Annekathryn Goodman. "The development of Qatar health care system: A review of the literature". International Journal of Clinical Medicine 6.3 (2015): 177-185.

10. Mahumud RA., et al. "Trend of healthcare expenditures in Bangladesh over last decades". American Journal of Economics, Finance and Management 1.3 (2015): 97-101.

11. Younies H., et al. "Healthcare forecasting in the united arab emirates (UAE)". Journal of Health and Human Services Administration 39.1 (2016): 3-14.

12. Arshad S., et al. "Health care system in pakistan; a review". Research in Pharmacy and Health Sciences 2.3 (2016): 211-216.
13. Erik Koornnief. "Progress and outcomes of health systems reform in the UAE: A systematic review". BMC Health Service Research 17 (2017): 672.

14. Mikhailitchenko A., et al. "An empirical insight: accountable care organizations' profitability and quality drivers". International Journal of Medicine and Public Health 10.4 (2020): 155159.

15. Wanyun Shao and Feng Hao. "Understanding American public support for covid -19 risk mitigation: the role of political orientation, socio-dermographic charecteristics, personel concern, and experience the united states 2020". International Journal of Public Health 66 (2021).

16. Ahmed A., et al. "Assessment of health literacy and its determinants in patients visiting tertiary care hospital, Rawalpindi, Pakistan". Pakistan Journal of Public Health 10.4 (2021).

17. Alyami H Alyami M., et al. "Coping strategies during the covid-19 pandemic and compliance with precautionary health behaviors: an online study among the Saudi adult population". Saudi Journal for Health Sciences 10.1 (2021).

18. Rahil A., et al. "Do the selection criteria of internal medicine residency program predict resident performance". Qatar Medical Journal 2 (2021): 20.

19. Setyawan FEB., et al. "Understanding patient satisfaction and loyalty in public and private health care". Journal of Public Health Research 9 (2021): 1823.

20. Vijayan SM., et al. "Facilitator and barriers of service utilization: perspective of stake holders in a family health center of central kerala- a qualitative study". Indian Journal of Public Health 65.2 (2021): 136-141.

21. Dickey $\mathrm{C}$ and Holzman E. "Behavioral communication strategies for global epidemics: an innovative model for public health education and humanitarian response". Strategies for Global Epidemics 22.4 (2021): 449-451.

\section{Volume 4 Issue 9 September 2021 (c) All rights are reserved by Said Alavi Kolambil.}

